\title{
O Queen, a Queen: Controvérsias sobre gêneros e performances ${ }^{12}$
}

Queen, the Queen: Controversies about gender and performances

\author{
Adriana Amaral \\ Professora do PPG em Comunicação da Universidade do Vale do Rio dos Sinos (Unisinos), Pós-Doutora em Mídia, Cultura e \\ Comunicação pela University of Surrey (Reino Unido), pesquisadora do CNPq e líder do GP CULTPOP. \\ <adriana.amaral08@gmail.com>
}

\section{Camila Monteiro}

Doutoranda em Música e Mídia na University of Huddersfield (UK), Mestre em Processos Midiáticos pela Universidade do Vale do Rio dos Sinos (UNISINOS).

<camila.monteiro@hud.ac.uk>

\section{Thiago Soares}

Professor do Programa de Pós-Graduação em Comunicação da Universidade Federal de Pernambuco (UFPE), Doutor em Comunicação e Cultura Contemporâneas (UFBA).

$<$ thikos@gmail.com>

\section{RESUMO}

A partir da apresentação ao vivo do grupo Queen, na edição 2015 do Rock in Rio, quando a banda inglesa de rock contou com um ex-integrante de reality show musical como vocalista, traça-se uma observação de controvérsias para pensar de que maneira as questões de gênero, com foco nas masculinidades, podem ser importantes ferramentas para pensar a construção do valor na música pop. A problemática trata das diferentes performances do masculino dos dois vocalistas (Freddie Mercury, o cantor original da banda, e Adam Lambert, no Rock in Rio 2015), evidenciando lugares distintos nas corporalidades da música pop, bem como a noção de trajetória como um aparato capaz de evocar princípios de autenticidade para os artistas. O procedimento metodológico foi a observação da performance a partir de três categorias de controvérsias: origens, gêneros musicais e corpos. A coleta de dados foi feita a partir da observação do YouTube, Twitter e de blogs LGBT. Como resultado inicial, indicamos que a governabilidade dos corpos numa performance, necessariamente, precisa reencenar outras performances; passando pela dicotomia em torno da presença numa atualização do ritual performático no qual noções como arquivo e repertório - propostas por Diana Taylor (2013) - são importantes para discutir as inúmeras possibilidades de tensões e controvérsias nestes espetáculos.

\section{ABSTRACT}

Based on the live performance of the group Queen in the 2015 Rock in Rio edition, when the British rock band featured a former member of reality musical show as a lead vocalist, we outline a controversy mapping to think about how gender issues, especially the debate on masculinity, can be important tools to think about the construction of value in pop music. The main issue relates to the different male performances of the two vocalists (Freddie Mercury, the original singer of the band and Adam Lambert, in Rock in Rio 2015), eliciting distinct places in the corporeality of pop music, as well as the notion of path as an apparatus capable to evoke principles of authenticity for artists. Our methodological process was the performance observation starting from three controversy categories: origins, music genres and bodies. The data was collected through YouTube, Twitter and LGBT blogs. As an initial result we indicate that the governability $f$ bodies in a performance necessarily needs to renacte another performances, including the dichotomy surrounding presence in an update of performatic ritual where notions of file and setlist - already discussed by Diana Taylor (2013) - are important to discuss multiple possibilities of tensions and controversies in these spetacles.

Keywords: Communication. Performance. Genres. 
18 de janeiro de 1985, Freddie Mercury senta ao piano - sobre o instrumento, copos de plástico, algo que parece uma partitura, tudo meio desajeitado - rosto suado, calor e umidade no verão carioca. Rio de Janeiro, Rock in Rio. No rosto, o indefectível bigode, uma certa inclinação para a direita, os olhos fechados. "She keeps Möet et Chandon in her pretty cabinet/ 'Let them eat cake' she says/ Just like Marie Antoinette", canta os primeios versos de "Killer Queen", canção composta pelo próprio Freddie Mercury, também pianista, que integrou o álbum "Sheer Heart Attack", de 1974. A música, aparentemente, fala sobre a vida de uma prostituta da alta classe, com muitas referências a marcas famosas e pessoas públicas. O solo de guitarra dessa canção se destaca e cria uma camada de sonoridades agudas em meio ao arranjo à base de piano. Freddie Mercury é o vocalista do Queen ${ }^{4}$.

18 de setembro de 2015, Adam Lambert senta num sofá roxo, delicadamente abre um leque dourado, cenografia irretocavelmente disposta num destacado do palco, os músicos ao fundo. Adam e seu microfone. 0 cantor "flerta" com a plateia, insinua disposições fálicas com o tal microfone. O palco é do Rock in Rio, a cidade é o Rio de Janeiro, passaram-se 30 anos. Adam Lambert também canta "Killer Queen", não há o piano, há um sofá. Não há o bigode de Freddie Mercury, há um topete nos cabelos lisos de Adam. Não há os pelos corporais visíveis de Freddie Mercury, há uma sobrancelha torneada. O arranjo pouco mudou. A voz de Adam Lambert alcança notas que o aproximam do virtuosismo vocal de Mercury. Talvez o sofá e o leque que

1 Pesquisa financiada pelo CNPq e pela CAPES, também sendo parte dos resultados das pesquisas da Rede PROCAD CAPES UFF-UNISINOS-UFPE.

2 Artigo apresentado no GT Estudos de Som e Música do 25o. Encontro Nacional da Compós, 2016, na Universidade Federal de Goiânia.

3 Lançada como single, "Killer Queen" foi um dos primeiros sucessos da banda Queen, alcançando o segundo lugar nas paradas britânicas e o décimo primeiro lugar nos Estados Unidos. Em 1986, foi lançada como faixa extra do álbum "Who Wants to Live Forever".

4 Queen é uma banda britânica de rock, fundada em meados de 1970, formada por Brian May (guitarra e vocais), Freddie Mercury (piano e vocais), John Deacon (baixo) e Roger Taylor (bateria e vocais). O grupo tornou-se internacionalmente conhecido através dos álbuns "Sheer Heart Attack" e, principalmente, "A Night at The Opera". A popularidade do quarteto estendeu-se com o disco "News of The World", de 1977, devido aos hits "We Will Rock You" e "We are the Champions", bem como com "Crazy Little Thing Called Love" e "Another One Bites the Dust", do elogiado álbum "The Game", de 1980. Em 1991, o então vocalista da banda Freddie Mercury falece em decorrência da Aids, em Londres. E em 1995, o baixista John Deacon voluntariamente se "aposenta" do meio musical. Os integrantes remanescentes Brian May e Roger Taylor seguiram com as suas carreiras solo, também tocando com músicos convidados o repertório do Queen. Dentre eles, destacam-se Paul Rodgers e Adam Lambert, com quem formaram, respectivamente, os projetos Queen + Paul Rodgers e Queen + Adam Lambert - este último foi a atração de abertura do Rock in Rio 2015, no Rio de Janeiro. 
integram a apresentação ao vivo de Adam Lambert façam alguma referência à personagem histórica de Maria Antonietta, presente na letra da canção e que, de alguma forma, integra um dos imaginários possíveis da canção. O corpo de vestígios evidentes de masculinidade de Freddie Mercury dá lugar a um corpo com rasuras de feminilidade de Adam Lambert.

Entre a apresentação de Freddie Mercury no Queen, em 1985, e a de Adam Lambert, em 2015, o Queen passou por perdas, reencenações, novas possibilidades de voltar aos palcos. Um grupo emblemático, que já vendeu mais de 300 milhões de álbuns ao redor do mundo, em função de um conjunto de imagens que legou para a música pop, e diante do envelhecimento dos seus integrantes passa a operar - marcadamente - sob a égide do que podemos chamar de espetáculos de "arquivo" (Taylor, 2013). Trata-se da perspectiva de reencenação do arquivo ou da "memória arquival", que seria, nas palavras de Diana Taylor, corporificar documentos pré-existentes (mapas, textos literários, cartas, restos arqueológicos, vídeos, filmes etc). Apresentamos aqui, uma primeira problemática, no que diz respeito à apresentação do Queen no Rock in Rio, em 2015: a fratura existente entre aquilo que se vê ao vivo, no presente, e o que se viu, há 30 anos, no mesmo evento.

A apresentação ao vivo de uma banda como o Queen apresenta questões no contemporâneo que dizem respeito a ideias em torno da relação entre memória e nostalgia. No entanto, vamos optar por pensar não através destes itinerários, mas, sim, debatendo a relação entre as apresentações ao vivo do Queen de 1985 e do Queen + Adam Lambert de 2015 como problemas de performance que dizem respeito a uma relação entre "arquivo" e "repertório". Aquilo que se enxerga no presente está impregnado de uma "memória arquival", pensando o arquivo como o "arkhé", o começo, uma primeira instância, um "governo".

Debatendo o arquivo como um "governo", a memória arquival sustentaria alguma governabilidade sobre os corpos que reencenam o arquivo, uma dinâmica de poder e disciplina que, no caso específico da música, evocaria noções valorativas. Reencenar com destreza e perfeição o arquivo seria uma forma de evidenciar um jogo de reverência e ciência de governabilidade. Ao assistir a um show do Queen em 2015 alguns indícios de repertório parecem evidentes: a imagem de Freddie Mercury aparecendo no telão do espetáculo, a reencenação do "coro" de "Love of My Life" exatamente como ocorrido em 1985 e documentado pelas equipes de televisão, os traquejos vocais de "Bohemian Rhapsody" como cristalizados no videoclipe da canção. Pode se pensar numa espécie de condução performática evocada pelo corpo de Freddie Mercury 
sobre o que vai se assistir numa nova apresentação ao vivo. Uma sombra. Uma fantasmagoria. A sustentação de uma imagem arquival.

Nosso interesse aqui não seria pensar apenas sobre a "restauração" de um ato performático (como evocaria Richard Schechner) ou sobre uma espécie de "determinação" de governabilidade sobre os corpos daqueles que reencenam o Queen. Estamos em busca de mapear as controvérsias da aparição do Queen em 2015. Quando pensamos nestas controvérsias, fugimos das relações binárias entre fenômenos e seus efeitos, suas causas, derivamos de uma ligação cartesiana entre o acontecimento e o acontecido. Problematizar as performances estaria na ordem de apresentar pontos de fuga e adesão sobre um fenômeno. Aquilo que parece ser a fissura do presente.

\begin{abstract}
A memória incorporada está "ao vivo" e excede a capacidade do arquivo de captá-la. Porém isso não significa que a performance - como comportamento ritualizado, formalizado ou reiterativo desaparece. As performances também replicam a si mesmas por meio de suas estruturas e códigos. Isso significa que o repertório, como o arquivo, é mediado (Taylor, 2013, p. 51).
\end{abstract}

Da passagem de Diana Taylor, destacamos dois momentos: o primeiro, em que, mesmo considerando a presença da "memória incorporada" no "ao vivo", a autora postula uma tangente na reiteração: toda reencenação traz à tona novas ritualizações que apresentam suas próprias estruturações e codificações. 0 segundo indica que a relação entre arquivo e repertório se dá na mediação, ou seja, na borda entre matrizes culturais e formatos industriais (Martín-Barbero, 2003, p. 16), nas articulações entre modos de produção e formas hegemônicas de comunicação coletiva, modos de interpelação dos sujeitos e de representação dos vínculos que dão coesão. Nas palavras de Martín-Barbero, "a mediação das ritualidades remete-nos ao nexo simbólico que sustenta toda a comunicação: à sua ancoragem na memória, aos seus ritos e formas, seus cenários de interação e repetição" (Martín-Barbero, 2003, p. 19). Pensando no que a ritualidade aciona a mediação, o autor segue:

As ritualidades constituem gramáticas de ação - do olhar, do escutar, do ler - que regulam a interação entre os espaços e os tempos da vida cotidiana e os espaços e tempos que conformam os meios, remetendo às múltiplas trajetórias de leitura ligadas às condições 
sociais do gosto e por posses e saberes constituídos na memória étnica, de classe ou de gênero (Martín-Barbero, 2003, p. 19).

Estabelecemos aqui uma triangulação que nos remete a pensar a presença do grupo Queen no Rock in Rio, trinta anos depois, como:

a) uma complexa cadeia de sentidos entre arquivo e repertório, aquilo que foi e que está sendo, as inúmeras fissuras possíveis entre passado e presente, nostalgia e atualização, sem uma precisão binária ou um claro foco;

b) um jogo de poder e governabilidade entre atos performáticos, que corpos guiam ou são guiados, o que deriva, tangencia, mantém-se ou sai da norma - "norma" esta constituída fortemente em relação ao arquivo e à memória incorporada;

c) uma "coreografia de sentires" (Taylor, 2013, p. 50) no estado constante do agora, entre uma certa ideia de fuga e de "manutenção de uma ordem social repressiva". A partir destes três pontos de partida, propomos mapear controvérsias em torno da presença do cantor Adam Lambert no projeto Adam Lambert + Queen, no Rock in Rio. Tomamos o debate sobre gênero (e as matrizes de masculinidades) como importante baliza valorativa na música pop estabelecendo conexões com algumas ideias em torno dos gêneros musicais.

\section{Controvérsias de origem: "Queen recruta cantor do American Idol?"}

Uma semana antes de se apresentar no Rock in Rio, o portal de notícias G1 estampou a manchete: "Adam Lambert diz que alguns fãs do Queen 'enchem o saco' dele nos shows". Há, na matéria, uma entrevista por telefone com o cantor, que afirma: "Algumas vezes, tentam tumultuar, enchem o saco durante o show, mas lá pela quarta música, estão dançando. Tem sido um desafio" (Lorentz, 2015, p. 1). A reportagem inicia traduzindo a dificuldade de "assumir o microfone" de Freddie Mercury e que Adam tem sido "bem recebido pela maioria dos fãs do Queen" (Lorentz, 2015). Curioso é que, ao final do texto, há uma retranca intitulada "Começo no American Idol", em que o repórter relembra o passado de Adam Lambert como ex-integrante de um reality show musical. Está no texto: "Adam Mitchel Lambert ficou famoso ao terminar com o segundo lugar no 'American Idol', em 2009. O Queen sempre esteve em seu repertório, voltado para músicas com pegada teatral" (Lorentz, 2015). De fato, Adam Lambert cantou Bohemian Rapsody"5 na sua audição para o programa e,

5 Audição de Adam com Bohemian Rapsody. Disponível em: <https://www.youtube.com/ watch?v=xnWyHIW9Hro\&ab channel=CristianoScorsetti>. Acesso em: 10 jan. 2016 
na final do atrativo televisivo, junto com os integrantes do Queen, entoou "We are the Champions", fazendo dueto também com o outro finalista do programa, Kris Allen ${ }^{6}$.

A aparição de Adam Lambert para o meio musical através de um reality show como o American Idol evocaria uma controvérsia sobre noções como "autoridade" para ocupar o "cargo" de vocalista de uma banda de rock como o Queen. Famoso por revelar cantores para a música pop (Mcready, 2015)7, o American Idol é um programa de televisão que coloca em questão a ideia de artista musical. De acordo com Heitor Luz (2013), a noção de artista dentro do star system musical

remete a uma construção cultural que se dá em torno de um personagem legitimado, reconhecido a partir da individualização e de seu talento. Tal ideia é engendrada pela indústria, partilhada e disputada pelo público, veículos de comunicação e pelos próprios pares (artistas já estabelecidos no meio musical), atores e agentes importantes no processo de consagração simbólica e mercadológica (Luz, 2013, p. 57).

Se pensarmos na origem midiática de Adam Lambert num reality show musical, poderíamos mapear uma controvérsia em torno da noção de talento. Num certo sentido, reality shows musicais seriam lugares de "fabricação" de artistas, dentro de uma premissa claramente mercadológica e serializada. Numa nomenclatura proposta por Márcia Tosta Dias (2000), dentro dos sistemas das gravadoras e do mercado da música, os "cantores de reality show" seriam como "artistas de marketing"8, que sofrem com o processo de deslegitimação, por serem criados sobretudo a partir de modismos. Produtores musicais acabariam sendo reconhecidos como "o cérebro criador por trás de discos e canções" dos "artistas de marketing". No entanto, a trajetória de Adam dentro do American Idol criou brechas nesta premissa de cooptação: logo após a audição do cantor ainda na fase classificatória ${ }^{9}$ circularam imagens dele com seu namorado,

6 Peformance de Adam e Kris com a banda Queen na final do programa. Disponível em: <https:// www.youtube.com/watch?v=0BiegN4-iT4\&ab channel=LexieeLambert>. Acesso em: 10 jan. 2016.

7 Kelly Clarkson, Carrie Underwood, Jennifer Hudson, Fantasia Barrino, Phillip Phillips, Jordin Sparks, Chris Daughtry são alguns dos cantores saídos do programa que atingiram sucesso não só na música como no teatro e cinema.

8 O oposto do "artista de marketing" seria o"artista de catálogo", com potencial de maior credibilidade e durabilidade.

9 A estrutura do reality show musical American Idol na ocasião de Adam Lambert como concorrente obedecia a etapas, em que os candidatos vão ultrapassando as fases até chegar na final. A primeira delas, chamada de "audition" ("audição), consiste em apresentações sem acompanhamento instrumental dos candidatos em diversas cidades dos Estados Unidos. Três jurados avaliam o candidato, indicando se 
vestido de mulher e fazendo performances extravagantes no "tradicional" festival psicodélico Burning Man e no Zodiac Show. Adam Lambert, ao participar do reality show, já tinha uma banda, The Citizen Vein, e gozava de relativo sucesso no meio underground californiano. Participava da banda também o músico Monte Pittman, que viria a se tornar, depois, um dos principais músicos de Madonna. Paralelo a isso, Adam já tinha um background considerável cantando no teatro musical: fez parte da turnê européia do musical "Hair", além de ser o "understudy" (substituto) de Fiyero em "Wicked", dois dos musicais mais populares na Broadway/West End. Acrescente-se também o fato dele já ser amigo de estrelas do star system musical americano como a cantora Katy Perry, que chegou a fazer uma apresentação ao vivo no programa usando uma capa (Katy, 2009) com o nome dele - causando ainda mais polêmica, pois poderia haver "favorecimento" do cantor na competição, uma vez que ele não era um completo desconhecido.

A combinação de vocalista de rock, gayassumido ${ }^{10}$, com relativa circulação no meio musical e notável extensão vocal destacou o artista. Polêmicas fotos "comprometedoras" apareciam na web (Dish, 2009), enquanto Adam continuava traçando sua trajetória muito particular no American Idol. Ainda na fase de audições, enquanto circulavam imagens dele maquiado à frente de sua banda de rock (glam rock?), Adam entoou uma versão lenta e acústica de "Believe", sucesso dançante da cantora Cher - uma espécie de "hino gay" das pistas de dança no final dos anos 1990. A sagacidade para negociar com matrizes ora "de nicho", ora hegemônicas na cultura musical, foi posicionando Adam Lambert num lugar privilegiado no programa. Na segunda semana de shows ao vivo (os live shows), cujo tema foi música country (gênero musical marcado por perspectivas conservadoras nas performances), ele cantou o clássico Ring of Fire, de Johnny Cash, com luvas, blazer prateado e unhas pintadas - numa clara "queerização" de um cânone do gênero musical. Essa performance pode ser considerada o "ponto de virada", de Adam Lambert, na competição por ter dividido o público. O mais importante jurado do programa, Simon Cowell, não gostou da apresentação, enquanto segmentos de fãs do artista o defendiam nas redes sociais.

ele deve ou não passar para uma próxima fase. Em seguida, há os chamados Top 24, Top 12 (com 24 concorrentes e 12 concorrentes) e, em seguida, passa-se para as etapas "ao vivo".

10 Adam nunca escondeu sua sexualidade durante o programa, diferente de outros candidatos - Clay Aiken, o mais conhecido deles - que preferiam não discutir o assunto. 
Foi, entretanto, o reconhecimento dos pares (os integrantes do Queen, Brian May e Roger Taylor) que fez com que Adam Lambert adentrasse num processo de consagração - para além da já mercadológica. Na final do American Idol, em 2009, Adam teve seu primeiro contato com a banda Queen, quando ele e outro finalista, Kris Allen, cantaram "We are the Champions" juntamente com integrantes originais da banda". Logo após a apresentação, inicia-se um "buzz" nas redes sociais - fortemente motivado por fãs do artista - sugerindo Adam como um "excelente vocalista para o Queen". Então, recém-separados de Paul Rodgers, que se juntou à banda de 2004 a 2009 para o projeto Paul Rodgers + Queen, Brian May disse, em entrevista ao The Guardian, ter interesse em trabalhar futuramente com Adam, gerando uma matéria em tom de incredulidade cujo título foi: "Queen recruta cantor do American Idol?" (Michaels, 2009, online). Enquanto as negociações para que Adam Lambert iniciasse seu projeto com o Queen, o cantor se apresentava junto a ex-candidatos do American Idol numa turnê cantando, entre outras, as canções "Life on Mars" de David Bowie, "Starlight" do Muse e "Whole Lotta Love" do Led Zeppelin.

Após esta turnê, lançou seu primeiro disco, "For Your Entertainment", seguido de sua primeira turnê solo, "The Glam Nation Tour" (2010-2011). A combinação "passado de American Idol" e "afetação" de Adam eram tópicos constantes de discussão entre fãs do artista e do Queen, por isso, a aproximação Adam + Queen foi feita com cautela. Em julho de 2012, sem muito alarde, foram anunciados dois shows em Londres, no Hammersmith Apollo, um local consideravelmente menor do que os estádios em que a banda costumava tocar. Os ingressos esgotaram rapidamente e a parceria recebeu críticas positivas. Paralelamente à parceria, Adam gravava seu segundo disco, "Trespassing", onde trabalhou com produtores importantes da música pop, como Nile Rodgers (exintegrante do grupo Chic e produtor, entre outros, de faixas pop como "Like a Virgin", de Madonna), Pharrell Williams (reconhecido por suas produções de artistas da música negra), além de Sam Sparro e Dr. Luke. Em 2010, Adam Lambert iniciou sua segunda turnê, a "Glamily Tour", para promover o álbum.

Foi em 2014, que Adam "oficialmente" se juntou ao Queen para uma série de shows pela Europa e Estados Unidos - com estratégica parada como atração de abertura do Rock in Rio. $O$ ano de 2015 foi também o que Adam também lançou seu terceiro disco, The Original High, cujo single, Ghost Town, foi incluído no repertório do show junto com o Queen.

11 Em uma das audições para Adam ingressar no programa ele cantou "Bohemian Rhapsody", outro clássico do Queen. 


\section{Controvérsias de gêneros musicais: "I'm Here for your Entertainment"}

Como é usual entre grupos de rock que orbitam no mainstream, o Queen sempre esteve num entre-gêneros dentro do próprio rock: hard rock, ópera rock, glam rock, arena rock, rock progressivo e até experimentações mais eletrônicas da ordem do synthpop e newromantics nos anos 80 pautaram a carreira dos britânicos. Nosso entendimento aqui, para além de uma categorização dos subgêneros como forma de orientação de consumo, é de pensar que agenciamentos há em debater o Queen no ano de 2015 $5^{12}$. O grupo estaria dentro do que Ken Barnes (1988) vai chamar de "rock clássico", ou seja, "o conjunto de artistas do rock 'testados e aprovados', em geral, de larga trajetória, que encontra reconhecimento, goza de popularidade e poder memorialista junto às audiências roqueiras" (Barnes, 1998, p. 43).

De qualquer forma, os subgêneros com os quais a banda se vinculou sonora e visualmente em determinadas fases podem ser articulados tanto às tendências mercadológicas de cada período quanto a rupturas em uma sonoridade mais clássica do rock progressivo - com o qual a banda inicialmente é rotulada pela imprensa. A negociação simbólica do popular, ou pop, os posiciona de certa forma em dois polos das controvérsias de gêneros musicais:

a) o dos artistas/bandas que podem - ou se dão ao direito - de experimentar vários gêneros e estilos dentro de um mesmo gênero, neste caso, o rock - o que pode incorrer em uma aceitação ou rejeição por parte dos fãs, que muitas vezes, se sentem "traídos" pelas mudanças ${ }^{13}$;

b) odosartistas/bandas que passama serclassificados mais genericamente como "pop", em decorrência da popularidade alcançada, que, de certa forma, faz com que fãs percebam fugas, derivas e oscilações dentro do "projeto roqueiro", sobretudo quando grupos começam a ter a imagem vinculada a grandes concertos nos quais estrelas do pop também estão presentes, como é o caso do próprio Rock In Rio ${ }^{14}$.

12 Cientes de que os estudos de gêneros musicais tratam de formas de endereçamento, o recorte temporal sobre uma banda de larga trajetória midiática como o Queen se faz necessário para que não se incorra na falácia de categorizar o grupo em função - exclusivamente - de seu passado. Pensamos que uma abordagem temporal sobre o momento dos artistas musicais em relação aos endereçamentos de gênero é oportuna.

13 Lembremos a paradigmática guinada do U2 em direção à experimentação com a música eletrônica e ao Krautrock mais obscuro nos anos 90, composta pela trilogia de álbuns Achtung Baby, Zooropa e POP, fazendo com que parte dos fãs e da crítica tenha reconhecido a "perda" de uma aura política e roqueira da banda.

14 As polêmicas que envolvem o próprio festival - sobretudo em discussões nos sites de redes sociais em todas as edições mais recentes - mereceriam um estudo à parte, uma vez que para muitos fãs de rock, o nome Rock In Rio indexaria o evento a um gênero musical que, para eles, não é representado 
Em relação às corporalidades articuladas a gêneros musicais, tanto o opera rock quanto o glam rock, o hard rock e o synthpop se inserem em tradições na qual a performatividade e o próprio visual trazem apropriações e negociam com a feminilidade ${ }^{15} \mathrm{em}$ constraste com a masculinidade do rock clássico. A figura de Freddie Mercury nos dá indicativos e rastros dessas brechas fluidas entre gêneros que aparecem em suas aparições. Percebe-se arqueologicamente que certos binarismos de gênero são reforçados nos gêneros musicais ${ }^{16}$ quando masculinidades e feminilidades encontram categorizações relativamente estáveis nas articulações entre o rock e o pop - por exemplo. Nesse caso, pensando o Queen nesse entre-lugar de subgêneros do rock, é possível articulálo também a um deslizar constante entre corporalidades consagradas do rock e também do pop. À frente dos vocais e ao piano no Queen, seria impossível não assistirmos a uma apresentação de Freddie Mercury sem lembrarmos tanto de Little Richard (pela certa violência ao piano em Long Tall Sally, por exemplo) quanto de um Elton John de roupa prateada também ao piano entoando Crocodile Rock.

Esse tipo de controvérsia também está relacionada às negociações dos diferentes espaços da performance, como nos indica Cynthia Fuchs (1998, p.108). A partir da análise de alguns artistas da cena Queer Punk, a autora trata das diferentes performances e performatividades de gênero das bandas em relação a suas audiências. Um dos casos analisados é da banda Pansy Division observada em um ambiente menor, um clube alternativo em Washington DC e na abertura da turnê da banda Green Day em uma arena em uma cidade suburbana da Virginia do Norte ${ }^{17}$. No ambiente menor, a banda formada por dois gays e um hétero era saudada pelas transgressões tanto nas letras que relatavam o cotidiano gay quanto pela "transgressão" do baterista hétero que usava um vestido de mulher em apoio aos outros integrantes do grupo. Essa

pelos artistas que lá se apresentam. Esse debate remete à discussão materialista sobre as definições de rock enquanto gênero indicadas por Kirschner (1998).

15 A ópera tem como um de seus expoentes a figura da Diva; o glam rock e o hard rock muitas vezes se utilizam de um visual composto por roupas e maquiagens consideradas no senso comum como de uso feminino; o synthpop e o new romantic, por suas melodias demarcadas pelos sintetizadores e pianos em vez da fálica guitarra, são comumente vinculados a "gêneros para garotas".

16 Em inglês, existem os termos genre (para gêneros literários, cinematográficos, musicais, etc.) e gender (para tratar das questões de identidade de gênero) o que impede o excesso de repetições. No português no entanto somos obrigados a repetir.

17 Fuchs (1998) comenta que, embora nem todos no clube alternativo sejam queer, ao menos durante o show, há uma espécie de emulação ou empatia que os faz embarcarem no apelo subjetivo da performance. Isso se dilui no processo da Arena, devido à especificidade desse tipo de subcultura. Todavia, não quer dizer que isso também não possa acontecer, a partir da negociação artista-audiência. 
dinâmica foi alterada no show da arena, com um público expressivamente maior e audiência feita de adolescentes e pais - e que não pareciam, segundo relata a autora, relacionados à cultura Queer Punk. Nesse show, a performance da banda estava mais agressiva em relação a questões políticas como a homofobia, por exemplo. Sendo o Green Day (o vocalista Billy Joe Armstrong é assumidamente bissexual) uma banda que possui conexões com essa cena, mas que se encontra no mainstream do pop rock, há uma mudança no tipo e endereçamento da performance.

No caso do Queen, no Rock in Rio de 2015, observamos que esse espaço amplo e heterogêneo do grande Festival e o espaço online dos comentários (no Facebook, Twitter e, sobretudo, no YouTube) se entrecruzam e desvelam novamente os binarismos relativos aos gêneros musicais e às performatividades de gênero (feminino e masculino), assim como a desconstrução destes endereçamentos, uma vez que o papel do espaço da performance funciona com a particularidade do momento. Como afirma Fuchs (1998, p. 103),

[...] o que eu quero salientar aqui é a interação produtiva da performance e autenticidade, as formas em que atos e intercâmbios sexuais podem "falar", exibir uma série de identidades que, em outros momentos são invisíveis precisamente porque estão ligados a tais atos e intercâmbios ${ }^{18}$.

Em vários momentos da performance de Adam Lambert com o Queen, a androginia, celebrada no glam rock e em subculturas como a pós-punk, gótica e clubber reaparece demarcada nos signos corporais do cantor, como os olhos maquiados de delineador preto, as botas e jaquetas destacadas na letra de um de seus hits, "If I Had You", em uma clara autorreferência. As transparências nas mangas, o colete e os maneirismos vitorianos sempre estiveram presentes tanto no glam quanto no chamado gothic rock e transgridem as performatividades de gênero desde o final dos anos 1970 e início dos anos 1980. Como afirma Brill (2008), a subcultura gótica sempre teve um apelo maior ao feminino, desconstruindo as normatividades do rock progressivo e de arena, gêneros em voga no mainstream nesse período e com os quais o Queen flertou.

Visualmente, Adam nos remete à definição de Goth Pop proposta por Edwards \& Monnet (2012) como uma espécie de tendência que borra as relações

18 Tradução nossa para: "What I want to stress here is the productive interplay of performance and authenticity, the ways that sexualized acts and exchanges can 'speak', display a range of identities that are otherwise rendered invisible precisely because they're attached to such acts and exchanges." 
entre performance e performatividade. Um modo pop contemporâneo que é fluido para dentro e para fora da cultura gótica. Uma manifestação do estilo e da estética gótica na cultura pop mainstream. Para os autores, um exemplo disso é quando itens que antes pertenciam ao consumo de nicho subcultural - roupas com caveiras, morcegos etc. - podem ser adquiridos em grandes cadeias de lojas de departamento ou aparecem no visual de pessoas comuns e artistas pop, não necessariamente vinculados à cena gótica. Além do visual Goth Pop, Adam Lambert também incorpora uma sonoridade mais dance, típica da cultura clubber ao amplo espectro de gêneros musicais que o Queen trabalhou em sua trajetória musical. Assim, novas controvérsias em termos de sonoridades, gêneros e corporalidades são expostas na performance do festival.

\section{Controvérsias dos corpos: I Want to Break Free}

Discutir as performances do Queen a partir dos corpos dos vocalistas, Freddie Mercury e Adam Lambert, implica em reconhecer que estamos diante de um "problema de gênero" (Butler, 2015). Numa primeira leitura, podemos pensar as abordagens de gênero como grandes campos de embates em torno de masculinidades e feminilidades, adesões e opressões, reiterações e apagamentos. No entanto, esta chave de interpretação cairia na mesma falácia que os próprios estudiosos sobre gênero tanto criticam - o binarismo - e apontariam, portanto, soluções ancoradas em torno de um claro embate (para usar a metáfora bélica: um "inimigo"). Talvez o desafiador é reconhecer que uma abordagem de gênero ancorada sobre a ideia de "recusa ou adesão" estaria centrada numa observação do fenômeno que excluiria suas contradições, seus embates "internos" e múltiplos agenciamentos. Portanto, a tentativa aqui é perceber que o debate em torno das premissas de gênero deve ser pensado na ordem das efemeridades, dos acontecimentos em situações, de uma certa ordem enunciativa que se faz e se desfaz constantemente, afirmando e negando na mesma proporção, na mesma intensidade, provocando anulações, deslocamentos, inclinações, desníveis. Dessa maneira,

gênero é a estetização repetida do corpo, uma série de atos que se repetem dentro de um enquadramento regulatório altamente rígido, que se cristaliza ao longo do tempo para produzir a aparência de algo sólido, um tipo natural de ser (Butler, 2015, p. 43-44).

Ideias sobre gêneros consistem na acumulação do que está do lado de fora (na cultura) fazendo crer que se trata de uma expressão de dentro (da 
natureza). Feminilidade e masculinidade, portanto, seriam mais do que simples expressões, "desempenhos culturais" em que a ideia de naturalidade seria constituída por meio de atos performativos limitados pelo discurso criando um efeito de "natural", inevitável. Cabe pensarmos como os "problemas de gênero" adentram à esfera da cultura musical, em que artistas e personagens estão em constante negociação, aparição e desaparecimento. Neste sentido, cabe questionarmos: masculinidades e feminilidades em corpos de artistas musicais são efemeridades que se materializam em apresentações ao vivo, videoclipes, shows, redes sociais, sempre mediadas, seja por dispositivos tecnológicos ou por agenciamentos/gerenciamento de carreiras, funcionando também como estratégias de marketing que visam posicionar artistas no mercado e diante de (novas) audiências.

Aqui, vamos nos dirigir ao campo das masculinidades tentando estabelecer articulações entre os olhares em torno de masculinidades dominantes e dissonantes, reconhecendo não os binarismos, mas os resíduos de ações performáticas de uma na outra. Lembramos aqui do clássico texto de Anthony Easthope (1986), What a Man's Gotta Do, em que o autor discorre sobre o mito da masculinidade dominante, a partir do engendramento da masculinidade heterossexual, patriarcal, vigorosa. Embora bastante criticado pelo olhar, de certa forma clichê em torno do masculino (o que traria uma certa visão essencialista do masculino a partir de ideias como vigor, controle e sagacidade), pontuo aqui que olhando de forma mais detida para os argumentos de Easthope, podemos perceber comentários sobre a dificuldade de lidar com o cânone da masculinidade - de alguma forma, o autor parece estar falando sobre os regimes de entrada-e-saída das masculinidades hegemônicas.

O enquadramento de Easthope se assemelha ao do sociólogo Pierre Bourdieu (1998) que, ao invés de falar "masculinidades dominantes" investiga a dominação masculina como um processo de reprodução de práticas consensuais. O foco de Bourdieu é o debate do que o autor chama de habitus, ou seja, um conjunto de ações reiterativas que agem como uma força, conduzindo corpos, disciplinando ações, engendrando performances e, portanto, valores. Pedimos especial atenção à noção de masculinidade como um valor, que aparece de forma periférica em Bourdieu, mas que ganha uma especial atenção sobretudo nas articulações com gêneros musicais. De alguma forma, estamos aqui traçando esboços conceituais que deem conta da problemática de gênero como uma forma de pensar as performances na música pop. Sobre a apresentação ao vivo de Adam Lambert, a principal contradição está em torno da problemática de gênero, mais detidamente, da masculinidade dissonante. "No Palco Mundo, 
com uma coroa de brilhantes e todos os holofotes voltados para ele, Adam foi mesmo uma rainha. E uma rainha bicha, já que a palavra "Queen" é utilizada como xingamento contra gays afeminados também", relata Fabrício Longo (2016), do blog Os Entendidos, do Portal Fórum. O lugar de fala de um blog gay elogia a mise-èn-scene de Adam, chamando o cantor de "rainha" (tradução para "queen").

No mesmo contexto de mídias de nicho, o blog Obvious, reconhece que houve resistência à performance de Adam Lambert:

O que motivou uma penca de autodenominados "alternativos" e "entendedores" a destratarem o talento de Adam Lambert foi mais do mesmo: o imperdoável atentado que os homens cometem contra sabe Deus quem ao possuírem trejeitos afeminados (Borges, 2015).

Foi curioso o destacamento desta problemática dos "trejeitos afeminados" de Adam Lambert por dois veículos voltados para o público gay. Na crítica do show publicada na edição online da revista Rolling Stone, o texto, que não vem assinado, apenas descreve o espetáculo, enumerando canções e descrevendo reações de músicos e do público. Mas, em determinado momento, há uma curiosa pontuação sobre o espetáculo: “Em 'Killer Queen', Lambert mostrou a extravagância das roupas e do jeito de cantar, se apresentando sentado em um sofá de veludo rosa, abanando-se com um leque e tomando champanhe. 'Rio, olá. Estão se divertindo?', disse ele, em inglês". Mesmo sem se referir abertamente sobre a suposta "feminilidade" do artista, a Rolling Stone refere-se a Adam Lambert como "extravagante", destacando que a apresentação se deu num sofá cênico. Aparentemente estamos diante da visualização de um desvio.

Pensar o desvio é uma das partituras propostas por autores que se propõem a debater o "queer", ou a diferença dentro de espaços previamente - e culturalmente - codificados. Se é possível falar sobre um "projeto queer", ele está em "reconhecer e atacar a naturalidade de gênero e as ficções que apóiam a heterossexualidade compulsória" (Burston e Richardson, 1995, p. 1), num sentido mais amplo, a norma, o padrão, a codificação. Num ensaio chamado Rock and Sexuality, Simon Frith e Anthony McRobbie (1990) destacam a profunda relação entre o rock e expressões de masculinidade, investigando, para além das disposições cênicas (a guitarra como elemento fálico, a corporalidade bruta, gestualidade violenta), a pouca presença de mulheres e gays homens nos sistemas produtivos do mercado musical roqueiro bem como na crítica de música. Esta constatação parece engendrar, para além de uma "heterossexualidade compulsória" no rock, uma premissa de insurgência 
de masculinidade - que, embora questionada por instâncias do glam rock, por exemplo ${ }^{19}$ - parece ainda enraizada nos vestígios valorativos sobre uma "boa performance de rock".

Durante a apresentação do Queen, no Rock in Rio, fomos percebendo as diversas reações de estranhamento em torno da presença de Adam Lambert, no momento em que se desenrolava o espetáculo. A rede social de mensagens instantâneas, Twitter, é uma importante ferramenta de entendimento das ações no momento em que estão acontecendo, apresentando premissas instáveis e efêmeras sobre os fenômenos - que, num estudo sobre performance, soa profundamente desafiador e instigante. Como nos interessa mapear as controvérsias sobre a performance, reconhecemos pelo menos, que o valor da apresentação do integrante-convidado do Queen, de fato, passou pelo debate sobre gênero. O perfil Renata Dias (@_redias) atestou ainda no começo do espetáculo:"Quantaboiolicenesse Adam Lambert...saudadesFreddy!\#rockinrio". A referida "boiolice", gíria para o caráter afeminado, pode ser também uma forma coloquial e mais direta de falar sobre exagero e extravagância. Na mesma linha, o perfil Tua Mãe (@Rafa_Wolf) julga num parâmetro de masculinidade compulsória: "longe de mim querer julgar, mas esse adam lambert é meio afeminado né?". O estranhamento em torno da suposta feminilidade de Adam Lambert, ao longo da noite, vai se transformando no estranhamento pelo motivo de que o vocalista do Queen, Freddie Mercury, também fazia aparições em que encenava trejeitos afeminados. O perfil pedro rafhael (@falarafha) questiona: "Fã de freddie mercury reclamando do adam por ser afeminado?". Ao final do show, o perfil honeydukes (@unicornintheam), tuíta de forma irônica: "Pelo que eu vi a maioria adorou o adam lambert, e a minoria que não gostou são os que acham que o freddie não era afeminado (risos)".

Embora os usuários no Twitter, ao comentarem a performance de Adam Lambert, estabeleçam parâmetros igualitários na questão sobre "ser afeminado" entre Adam e Freddie Mercury (não deveria haver estranhamento com o fato de Adam Lambert ser afeminado uma vez que Freddie Mercury também era - e ambos eram gays), um olhar mais detido sobre a questão da performatividade de gênero (Butler, 2015), ou seja, a forma de encenação do gênero, a ideia de teatralização identitária em torno do que se mostra e do que se esconde sem ser, no entanto, uma prática voluntária, antes, é um processo contínuo de reiterações que vão se sobrepondo, se ajustando, se acomodando naquilo que

19 Artistas de outras cenas como o industrial rock por exemplo sempre desafiaram essas premissas: Marylin Manson em suas performances de palco e videoclipes aparecendo com peitos femininos e, numa instância mais radical Genesis P-Orridge, vocalista da banda inglesa Throbbing Gristle passou por cirurgias para ficar igual a sua ex-mulher. 
é visível na superfície de uma corporalidade. "A performatividade de gênero não pode ser teorizada à parte na prática forçosa e reiterativa dos regimes sexuais regulatórios e de nenhuma forma pressupõe um objeto de escolha" (Butler, 2015, p. 15). Ou seja, os acionamentos em torno das masculinidades e feminilidades, no momento em que estão aparecendo, naquilo que Butler chama aqui de performatividade tem a ver com a maneira com que os corpos se apresentam, com que os enxergamos. No caso específico do espetáculo musical, haveria uma sobreposição ficcional, inventiva, em torno da performatividade - uma vez que estamos assistindo a um espetáculo e em que noções como entretenimento, ludicidade e diversão, estão em jogo.

Apoiando em Butler (2015), conduzimos nosso olhar para pensar que, sim, haveria diferenças entre as masculinidades afeminadas de Freddie Mercury e Adam Lambert. E estas diferenças estariam na ordem de como os corpos destes dois artistas encenam o feminino. Embora tenha usado figurinos extravagantes, coloridos e, em alguns momentos, afeminados, certamente, poderíamos elencar no corpo de Freddie Mercury a glorificação dos pelos masculinos: o cantor, em inúmeras de suas aparições, aparecia de bigode, não negava os pelos no tórax, peito e barriga. A presença dos pelos no corpo de Freddie Mercury parecia, de alguma forma, acionar uma certa rasura no seu projeto de feminilidade cênica. Mesmo que usasse roupas femininas, collants e shorts curtos e apertados, ainda assim, algo parecia vazar no projeto de feminilidade ou de masculinidade dissonante do líder do Queen. Se tomarmos outra imagem de Freddie Mercury como apoio argumentativo - ele vestido de mulher, com peruca e bigode no clipe de I Want to Break Free - reforçaríamos inclusive uma certa ideia paródica em torno do feminino: ao se vestir de mulher, Freddie Mercury, na verdade, parecia estar parodiando uma certa ideia de feminilidade.

Em contrapartida, a corporalidade de Adam Lambert, de rosto afilado, sem pêlos aparentes, sobrancelhas "desenhadas" e arqueadas, evocariam um tipo de projeto de masculinidade ainda mais turvo que o proposto por Freddie Mercury. As ideias de vivência de uma prática de se vestir de mulher, de se maquiar com frequência, de aparecer midiaticamente na companhia de drag queens, artistas da cultura de boates gays, impele a Adam Lambert um lugar de naturalização da feminilidade no seu corpo. Se pensarmos que a atividade da performance é sua teatralidade, a performatividade estaria na ordem de um processo contínuo de reiteração daquilo que forma a eficácia da performance - o arsenal cultural que nos move por outros corpos, outros gestos, fantasmagorias, por aquilo que julgamos ser uma forma bem-sucedida de performatizar. Neste sentido, Adam Lambert teatralizaria uma espécie de feminilidade romântica, calcada numa poética do corpo "ideal" do feminino no masculino; enquanto a teatralidade de 
Freddie Mercury poderia aparecer ancorada em traços humorísticos, paródicos - regulando as ficções sobre o projeto de masculinidade "carnavalizada".

\section{O Queen? A Drag Queen?}

Verificamos, ao longo deste artigo, problemáticas em torno da presença de um novo vocalista numa consagrada banda de rock. Da governabilidade dos corpos numa performance que, necessariamente, precisa reencenar outras performances; passando pela dicotomia em torno da presença (da baliza do que é inovação e "homenagem") numa atualização do ritual performático, noções como "arquivo" e "repertório" - conforme debate Diana Taylor (2013) - são importantes para discutir as inúmeras possibilidades de tensões e controvérsias nestes espetáculos "memorialistas". No caso específico do Queen, a partir de um debate que se inicia em veículos (de grande mídia e de nicho) passa por discussões em fóruns de fãs e chega a comentários nas redes sociais, percebemos que acionamentos em torno de contradições que dizem respeito, a trajetória/origem do artista em questão, os endereçamentos de gêneros musicais e a performatividade de gênero (masculinidades dissonantes) são aparatos para debater o valor na performance de música pop.

A discussão sobre a suposta feminilidade presente na performance de Adam Lambert estendeu-se durante todo o final de semana, nas redes sociais, a ponto do usuário Thalles F. Bragança (@Thallees) reclamar, no dia seguinte ao espetáculo: "Preguiça dessas pessoas que criticaram o show do Adam Lambert por ele ser afeminado e hoje vêm falar que rock de verdade é o do Metallica". Embora localizado e circunscrito a um comentário da rede social Twitter, este texto de @Thallees parece reativar um lugar binário de observação sobre valores das performances na música pop: "rock de verdade" seria masculino como o Metallica. Estaríamos diante de algumas "amarras" em torno das espectatorialidades dos espetáculos musicais da cultura pop - que embora sejam costumeiramente questionadas e problematizadas, ainda parecem negociar com a cristalização de masculinidades hegemônicas como aparatos valorativos. A forma jocosa de se referir à performance de Adam Lambert no Queen ganhou notoriedade quando o músico Dado Villa-Lobos (do Legião Urbana) atestou, em entrevista ao site Glamurama: "Esse maluco é uma bicha louca, parece uma drag queen, mas ele mandou muito bem". Se o problema de gênero também está na linguagem, usar "mas" (um senão) para se referir a um valor ("mandar bem") soa como uma espécie de concessão retórica para o "maluco", "bicha louca", "detonar" numa performance de rock. Ou seria "lacrar" numa performance pop? 


\section{Referências}

BARNES, K. Top 40 Radio: A Fragment of the Imagination. In: FRITH, S. Facing the Music. Nova York: Pantheon Book, p. 8-50, 1988.

BORGES, E. Vida longa à nova Rainha. Obvious Mag, 2015. Disponível em: <http:// lounge.obviousmag.org/sup3rtr4mp/2015/09/vida-longa-a-nova-rainha. html>. Acesso em: 08 jan. 2016.

BOURDIEU, P. A Dominação Masculina. São Paulo: Bertrand Brasil, 1998.

BRILL, D. Goth Culture: Gender, Sexuality and Style. Oxford: Berg, 2008. DOI: < $\underline{\text { http:// }}$ dx.doi.org/10.2752/9781847887184>

BURSTON, P. e RICHARDSON, C. A Queer Romance: Lesbian, Gay Men and Popular Culture. Londres: Routledge, 1995.

BUTLER, J. Problemas de Gênero: Feminismo e Subversão de Identidade. Rio de Janeiro: Civilização Brasileira, 2015.

DIAS, M.T. Os Donos da Voz. São Paulo: Boitempo, 2000.

DISH of Salt. 'Idol's' Adam Lambert On His Photo Scandal. Access Hollywood, 06 mar. 2009. Disponível em: <http://www.accesshollywood.com/articles/dish-of-saltidols-adam-lambert-on-his-photo-scandal-68499/\#gDY8PGY2fiEjlb1D.99>. Acesso em: 13 dez. 2015.

EASTHOPE, A. What a Man's Gotta Do: The Masculine Myth in Popular Culture. Londres: Paladin, 1986.

EDWARDS, J., MONNET, A. (Orgs). Introduction: From Goth/ic to Pop. In: EDWARDS, J., MONNET, A. Pop Goth: The Gothic in Contemporary Literature and Popular Culture. New York: Routledge, 2012.

FRITH, S.; McROBBIE, A. Rock and Sexuality. In: FRITH, S. e GOODWIN, A. (orgs) On Record: Pop, Rock and the Written Word. Nova York: Pantheon Books, p. 71-89, 1990.

FUCHS, C. If I Had a Dick: Queers, Punks, and Alternative Acts. In: SWISS, T., SLOOP, J. e HERMAN, A. (eds). Mapping the Beat: Popular Music and Contemporary Theory. Malden: Blackwell, 1998.

KATY Perry's Cape Crusade. TMZ. 18 mai. 2009. Disponível em: <http://www.tmz. com/2009/05/18/katy-perry-victim-of-an-a-i-caped-crusade/>. Acesso em: 3 fev. 2016.

KIRSCHNER, T. Studying Rock: Towards a Matherialistic Ethnography. In: SWISS, T., SLOOP, J. e HERMAN, A. (eds). Mapping the Beat. Popular Music and Contemporary Theory. Malden: Blackwell, 1998. 
LONGO, F. Banda "bicha", vocalista gay e um show super viado no Rock in Rio. Revista Forum, blog Os Entendidos, 20 set. 2015. Disponível em: <http://www. revistaforum.com.br/osentendidos/2015/09/20/bicha-vocalista-gay-showviado-rock-in-rio/>. Acesso em: 21 set. 2015.

LORENTZ, B. Adam Lambert diz que alguns fãs do Queen "enchem o saco dele" nos shows. G1. 10 set. 2015. Disponível em: <http://g1.globo.com/musica/rockin-rio/2015/noticia/2015/09/adam-lambert-diz-que-alguns-fas-do-queenenchem-saco-dele-nos-shows.html>. Acesso em: 12 fev. 2016.

LUZ, H. Televisão, Indústria da Música e Reality Show Musical no Brasil. Tese de Doutorado - Programa de Pós-Graduação em Comunicação. Niterói: Universidade Federal Fluminense, 2013. mimeo. 224.p.

MARTÍN-BARBERO, J. Dos Meios às Mediações. Rio de Janeiro: Editora UFRJ, 2003.

MCREADY, R. American Idol Ends: Look back at the 10 Most Successful Alums.

US Magazine, 15 nov. 2015. Disponível em: <http://www.usmagazine. com/entertainment/news/american-idol-ends-look-back-at-the-10-mostsuccessful-alums-2015115>. Acesso em: 2 dez. 2015.

MICHAELS, S. Queen to recruit American Idol Singer? The Guardian, 27 mai. 2009. Disponível em: <http://www.theguardian.com/music/2009/may/27/queenamerican-idol-singer>. Acesso em: 15 out. 2015.

TAYLOR, D. O Arquivo e o Repertório: Performance e Memória Cultural nas Américas. Belo Horizonte: Editora UFMG, 2013.

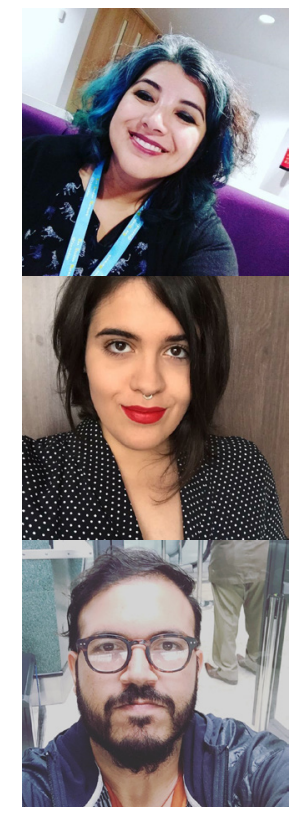

Recebido em: 05/05/2016.

Aceito em: 04/07/2016.

Endereço dos autores:

Adriana Amaral <adriana.amaral08@gmail.com>

PPG em Comunicação da Universidade do Vale do Rio dos Sinos (UNISINOS)

Av. Unisinos, 950 - Bairro Cristo Rei

93022-750 - São Leopoldo - RS - Brasil.

Camila Monteiro <camila.monteiro@hud.ac.uk>

Depto. de Música e Mídia da University of Huddersfield

Queensgate, Huddersfield HD1 3DH, Reino Unido

Thiago Soares<thikos@gmail.com>

PPG em Comunicação da Universidade Federal de Pernambuco (UFPE)

Centro de Artes e Comunicação

Av. Professor Moraes Rego, $\mathrm{s} / \mathrm{n}^{\circ}$

50670-901 - Recife - PE - Brasil 